\title{
Noise in neonatology: perception of health professionals
}

O ruído em neonatologia: perceção dos profissionais de saúde

El ruido en neonatología: percepción de los profesionales de la salud

Ernestina Maria Batoca Silva*iD; Ana Cristina Faria Silva Ramos**iD; João Carvalho Duarte***iD;

Daniel Marques Silva**** (D)

\begin{abstract}
Background: The negative impact of noise in the newborn in neonatology units, as well as in the parents and health professionals, is known, so it is essential to raise awareness of the reduction and control of this stressor agent.

Objectives: To identify the perception of health professionals about noise in neonatology.

Methodology: Qualitative-quantitative and descriptive study. A non-probabilistic sample of 52 health professionals. An ad-hoc questionnaire designed for this purpose was used.

Results: The majority of professionals considers neonatology units noisy and uncomfortable in performing functions and believes that noise has adverse effects, although there is little knowledge about the decibel values recommended for the neonatal unit.

Conclusion: The perception of health professionals about noise indicates the need to implement a noise reduction program. We consider the training and involvement of the team relevant, so professionals can be active and inciting in the adoption of measures that promote an acoustically healthy environment for the newborn and the well-being of parents and health professionals.
\end{abstract}

Keywords: noise; intensive care units, neonatal; health personnel; infant, newborn

\section{Resumo}

Enquadramento: É reconhecido o impacto negativo do ruído no recém-nascido em unidades de neonatologia, bem como nos pais e profissionais de saúde, sendo importante a sensibilização para a redução e controlo deste agente stressor. Objetivos: Identificar a perceção dos profissionais de saúde sobre o ruído em neonatologia.

Metodologia: Estudo quali-quantitativo e descritivo. Amostra não probabilística com 52 profissionais de saúde. Utilizou-se um questionário ad-hoc construído para o efeito. Resultados: Os profissionais, na sua maioria, consideram a unidade de neonatologia ruidosa, incómoda no desempenho de funções e consideram existir efeitos adversos do ruído, apesar de apresentarem poucos conhecimentos sobre os valores de decibéis recomendados para uma unidade neonatal.

Conclusáo: A perceção dos profissionais de saúde sobre o ruído indica a necessidade de implementação de um programa de redução de ruído. Considerou-se pertinente a formação e envolvimento da equipa, de forma a serem elementos ativos e mobilizadores na adoção de medidas que promovam um ambiente acusticamente mais saudável para o recém-nascido e bem-estar dos pais e dos profissionais de saúde.

Palavras-chave: ruído; unidades de terapia intensiva neonatal; pessoal de saúde; recém-nascido

*Ph.D., Coordinating Professor, Polytechnic Institute of Viseu, 3504-510, Viseu, Portugal [ernestinabatoca@sapo.pt]. (1) https://orcid.org/0000-0002-4401-6296. Contribution to the article: tinabatoca@sapo.pt]. O https://orcid.org/0000-0002-4401-6296. Contribution to the article:
bibliographical research; data collection; statistical treatment and assessment; data analysis bibliographical research; data collection; statistical treatment and assessment; data analysis
and discussion; writing of the article and final approval of to-be-published version. Address for and discussion; writing of the article and final approval of to-be-publishe
correspondence: Rua da Peça, n⿳亠丷厂 64 , Esculca, 3500-843, Viseu, Portugal.

Correspondence: Rua da Peça, no 64, Esculca, 3500-843, Viseu, Portugal.
**MSc., RN, Hospital Center of Vila Nova de Gaia/Espinho, 4434-502, Vila Nova de Gaia, Espinho, Portugal [ana.acts@gmail.com]. (10 https://orcid.org/0000-0002-7179-0439. Contribution to the article: bibliographical research; data collection; statistical treatment and assessment; data analysis and discussion; and writing of the article.

***:Ph.D., Coordinating Professor, Health School of Viseu, Polvtechnic Institute of Viseu, Portugal, member of Center for the Study of Education, Technologies, and Health (CSETH) and johnny@gmail.com]. (1) https://orcid.org/0000-0001-7082-8012. Contribution to the article: johnny@gmail.com]. (1) https://orcid.
statistical treatment and assessment

statistical treatment and assessment.
****:Ph.D., Coordinating Professor, Health School of Viseu, Polytechnic Institute of Viseu, Portugal, member of Center for the Study of Education, Technologies, and Health (CSETH) and of Health Sciences Research Unit: Nursing (UICISA:E), 3046-851, Coimbra, Portugal [dsilva. essv@gmail.com].@ https://orcid.org/0000-0003-4311-6014. Contribution to the article: data discussion and analysis; writing of the article, and final approval of to-be-published version.

\section{Resumen}

Marco contextual: Se reconoce el impacto negativo del ruido en el recién nacido en unidades de neonatología, así como en los padres y en los profesionales de la salud, por lo que es importante la sensibilización para reducir y controlar este factor de estrés.

Objetivos: Identificar la percepción de los profesionales de la salud sobre el ruido en neonatología.

Metodología: Estudio cuali-cuantitativo y descriptivo. La muestra fue no probabilística con 52 profesionales de la salud. Se utilizó un cuestionario ad-hoc construido para tal efecto.

Resultados: La mayoría de los profesionales consideran la unidad de neonatología ruidosa, incómoda en el desempeño de funciones y consideran que existen efectos adversos del ruido, a pesar de que presentan pocos conocimientos sobre los valores de decibelios recomendados para una unidad neonatal.

Conclusión: La percepción de los profesionales de la salud sobre el ruido indica la necesidad de implementar un programa de reducción del ruido. Se consideró pertinente formar e implicar al equipo, de forma que sean elementos activos y movilizadores en la adopción de medidas que promuevan un ambiente acústicamente más sano para el recién nacido y para el bienestar de los padres y de los profesionales de la salud.

Palabras clave: ruido; unidades de cuidado intensivo neonatal; personal de salud; recién nacido 


\section{Introduction}

The hospitalization of the newborn (NB) in a neonatal intensive care unit (NICU), how information is received, and the type of individual response to stress determine the changes related to the neurodevelopment (Coughlin, 2017). The adverse effects of the continuous exposure of infants to noise are known (Caple $\&$ Hurst, 2016), as well as on their parents and the professionals who work in neonatology (Pineda et al., 2017).

Various noise sources coexist in a NICU, being the human factor and the equipment considered as the primary sources of noise, which generates a stressful environment, although one acknowledges that much of this noise can be avoided or minimized, using low-cost and straightforward measures (Marques, 2014). The awareness raising of health professionals and their training in this field are necessary concerning the implementation of preventive and/or corrective measures for the environmental acoustic control (Carvalhais, Santos, Coelho, Xavier, \& Silva, 2016). As stated by Santana et al. (2015), only with a policy of continued education and the involvement of all professionals will the effects occur in the NICU environment.

Degorre et al. (2017) report that the lack of systematic monitoring of noise level does not allow its control and does not promote the implementation and maintenance of measures for the reduction of noise levels.

The interest in this study relates to the importance of promoting an environment that boosts the physiological stability of the NB and decreases the environment's negative impact, optimizing his/her growth and development and simultaneously providing the well-being of families and health professionals. This study aims to raise awareness for the promotion of noise reduction and sustainment of a noise reduction program in a NICU.

The objective of this study is to identify the perception of health professionals about the noise in neonatology.

\section{Background}

The concern for the maintenance of adequate levels of noise is not a current matter. In fact, the requirement of silence in hospital environments is one of the oldest traditions in the care of the sick person (Agência Nacional de Vigilância Sanitária [ANVISA], 2015) and the matter of hospital noise control is, currently, included in the manual of standards of hospitals (Direção-Geral da Saúde. Departamento da Qualidade na Saúde, 2016). There are recommendations of distinct entities for acceptable values or ideals of sound pressure levels for hospital environments and also for services of neonatology. White, Smith, and Shepley (2013) and Reeves-Messner and Spilker (2017) recommend that noise values between 46-50 decibels $(\mathrm{dB})$ should not occur in more than $10 \%$ of the time each hour and that the maximum sound pressure level (Lmax) must not exceed $65 \mathrm{~dB}$, which can only occur in instantaneous noise peaks.

Despite these recommendations, one acknowledges the existence of excessive noise levels in neonatal units, with values higher than those recommended. On average, studies conducted in neonatology show values of noise between 10 to $40 \mathrm{~dB}$ above the recommended values (Reeves-Messner \& Spilker, 2017). In addition to high sound pressure levels, the period in which they arise and the noise sources deserve special attention and are of great concern.

The crying of the NB inside the incubator can cause noise between 81 to $87 \mathrm{~dB}$ and thus it is important to promote his/her comfort, to decrease the crying episodes, and to respond as soon as possible to his/her weeping, as well as to alarms and equipment (Reeves-Messner \& Spilker, 2017).

Human attitudes are also identified as one of the main sources of noise and constitute 50\% of the noise-producing sources (Daniele, Pinheiro, Kakehashi, \& Balieiro, 2012). The high number of people who remain in the NICU, such as health professionals and parents, is also associated with significant changes in the noise level, which includes also visiting conversations, the use of telephones, and the shift pass-down of nursing and medical teams, possibly causing sounds of around 55.2 to $75.7 \mathrm{~dB}$ (Correia, Mendonça, \& Souza, 2014).

Other noise sources which contribute to the increase of environmental noise are related to the sources of oxygen and compressed air, working oxygen humidifiers, vacuum aspirator (Correia 
et al., 2014), and the use of oxygen supply to the NB by nasal cannula (Pineda et al., 2017). Despite having been considered for a long time an ideal microenvironment for the $\mathrm{NB}$, the incubator has currently raised issues related to its protection capacity, namely as regards the noise. In fact, the incubator works partly as an acoustics barrier of external environmental sounds, but the sounds produced by its functioning and the activities performed to the NB in its interior, as well as its manipulation and the placement of objects over it, the opening and closing of its doors to access the NB, any alarms from the incubator, and the conversations near it cause noise and amplify it (Correia et al., 2014). In this regard, the same authors add that the functioning of the incubator's engine can generate sounds of approximately $50 \mathrm{~dB}$. Even the type of materials used on the floorings is responsible for the noise if they do not possess an adequate quality of sound absorption (Agência Nacional de Vigilância Sanitária [ANVISA], 2015).

\section{Research question}

What is the perception of health professionals about the noise in neonatology units?

\section{Methodology}

This study is quali-quantitative and descriptive, with a non-probabilistic sample of 52 health professionals, $55.8 \%$ of which are nurses and $26.9 \%$ doctors, $13.5 \%$ operational assistants and $3.8 \%$ other professionals that work in the neonatology department (these include a physiotherapist and a technical assistant). The inclusion criteria are as follows: to perform regular functions in the neonatology department and to be present in the unit during the conduction of the study. The study received a favorable opinion by the Ethics Committee of the Hospital in the area of Greater Porto in the northern region of Portugal (Opinion no. 41/2017). For data collection, the researcher visited the unit and handed an envelope to each of the participants containing the questionnaire and the informed consent. After being filled, the questionnaire was returned to the head nurse and the head physician of the unit, who handed it to the researcher in a sealed envelope and without identification, to ensure the anonymization of participants. The study was conducted between June and August of 2017. The data collection instrument used was an ad-hoc questionnaire with questions of sociodemographic characterization and a Likert-type scale with five levels, 1 being the lowest and 5 the highest value, to identify the perception of health professionals about the noise in neonatology, including: the overall noise and acoustic comfort in the unit; influence of noise in the current state of the NB; implications in its development; effects on health of parents/ relatives and professionals; noise inconvenience in professional performance; knowledge related to the topic of noise and recommended decibels; concern about noise; contribution of behaviors and possibility of noise reduction. These questions were coded, and two cohort groups were defined, which made the variables dichotomic, to provide a comprehensive reading and analysis of the responses through the binomial test. We conducted a pre-test to six health professionals of the neonatology unit, which reflected the diversity of the sample: a doctor, four nurses, and an operational assistant. Following the pre-test, we performed an interview that allowed clarifying some concepts in the questions.

The instrument also contained open questions, and the content of the answers was analyzed according to Bardin (2016).

For the data analysis, we used the IBM SPSS Statistics program, version 24.0 for Windows 2016. The level of significance was 5\% ( $p=0.05)$.

\section{Results}

\section{Sociodemographic characterization}

The majority of health professionals are female (90.4\%), aged between 25 and 60 years old ( $M$ $=40.94 \pm 10.32$ years). We found that half had up to 38 years of age $(M d=38)$. We observed that the majority are nurses (55.8\%), 26.9\% are doctors, $13.5 \%$ are operational assistants, and $3.8 \%$ are other professionals/technicians, including a physiotherapist and a technical assistant. The time of professional experience varies between 2 and 39 years $(M=17.06 \pm$ 
9.75 years), and $40.4 \%$ have experience $\geq 21$ years. Experience in neonatology varies between 6 months and 30 years $(M=12.42 \pm$ 9.17 years).

\section{Perception about noise in neonatology}

To ascertain the perception of professionals about noise in neonatology, we studied the variables according to Table 1 and found that the minimum values range between 1 and 3, with higher mean values in the "effects on health of professionals" ( $M=4.42 \pm 0.54)$, in the "influence in current clinical status of NB" and "implications in the development of the NB" $(M=4.12 \pm 0.68)$, and lower values in "knowledge related to recommended dB " $(M$ $=2.29 \pm 0.75)$ and "knowledge related to the topic of noise" $(M=2.77 \pm 0.51)$.

Table 1

Statistics concerning the perception of health professionals about noise in neonatology

\begin{tabular}{|c|c|c|c|c|c|c|c|}
\hline Variables & Min & Max & $M$ & $S D$ & $\mathrm{CV}(\%)$ & $M d n$ & Mo \\
\hline Overall unit noise & 2 & 5 & 3.88 & 0.65 & 16.75 & 4 & 4 \\
\hline Comfort of unit's acoustic environment & 2 & 5 & 3.48 & 0.67 & 19.25 & 4 & 4 \\
\hline Influence of current clinical status of the NB & 2 & 5 & 4.12 & 0.68 & 16.50 & 4 & 4 \\
\hline Implications in development of the NB & 2 & 5 & 4.12 & 0.68 & 16.50 & 4 & 4 \\
\hline Effects on health and well-being of parents/relatives & 2 & 5 & 3.81 & 0.79 & 20.73 & 4 & 4 \\
\hline Effects on health of professionals & 3 & 5 & 4.42 & 0.54 & 12.22 & 4 & 4 \\
\hline Noise inconvenience in professional performance & 3 & 5 & 3.71 & 0.61 & 16.44 & 4 & 4 \\
\hline Knowledge related to the topic of noise & 2 & 4 & 2.77 & 0.51 & 18.41 & 3 & 3 \\
\hline Knowledge related to recommended $\mathrm{dB}$ & 1 & 4 & 2.29 & 0.75 & 32.75 & 2 & 2 \\
\hline Perceiving whether noise is higher than the recommended & 2 & 5 & 3.63 & 0.56 & 15.43 & 4 & 4 \\
\hline Concern about noise & 2 & 5 & 3.17 & 0.62 & 19.56 & 3 & 3 \\
\hline Contribution to behavior of professionals & 2 & 4 & 2.88 & 0.51 & 17.71 & 3 & 3 \\
\hline Possibility of noise reduction & 3 & 5 & 3.94 & 0.54 & 13.71 & 4 & 4 \\
\hline
\end{tabular}

Note. Min = Minimum; Max = Maximum; $M=$ Mean; $S D=$ Standard deviation; $C V=$ Coefficient of variation; $M d n=$ Median; $M o=$ Mode.

\section{Overall noise and comfort of the acoustic environment of the unit}

We found that the majority of the sample $(77 \%)$ considers the neonatology unit noisy, with statistically significant differences ( $\mathrm{Bi}-$ nomial $p=0.000)$. Nurses have greater perception of noise in the unit $(\mathrm{OM}=30.17)$, and operational assistants are the professional group with the lowest perception of noise level $(\mathrm{OM}=16.71)$. There are statistically significant differences between the perception of the noise level in the unit and the professional group $\left(X^{2}\right.$ $=7.717 ; p=0.021)$. Those who have professional experience $\geq 21$ years manifest greater perception of noise in the unit $(\mathrm{OM}=27.76)$, which does not observe statistically significant differences $\left(X^{2}=0.365 ; p=0.833\right)$.

About the "comfort of the acoustic environment of the unit", the majority of the professionals (54\%) consider it uncomfortable, and the binomial test did not verify a statistically significant difference $(p=0.678)$.

The room of the neonatology unit considered as the loudest was the room A (51.9\%), followed by the option all equally noisy with $36.5 \%$. Regarding the shift with the highest noise level, the more significant part of the sample (96.2\%) reported the morning shift as the noisier. No professional said the night shift as being the noisiest.

About the sources that cause the most noise in the neonatology unit ( 1 for the lowest noise source and 5 for the highest noise source), we 
found that $42.3 \%$ of professionals considered the equipment $(M=3.63 \pm 1.509)$. By descending order there are the conversations between elements of the team $(M=3.48 \pm 1.20)$, the provision of care/procedures $(M=2.73 \pm 1.27)$, followed by family visits $(M=2.60 \pm 1.332)$ and finally the telephone/cellphones $(M=2.56$ \pm 1.420 ).

The participants were asked whether they believed there are other noise sources in addition to those listed on the closed question. The answers included the following: unit doorbell, existing radios in the unit, telephone service, garbage bins, and clothing baskets, NB crying, opening and closing doors, opening and closing drawers and cabinets, and the handling of materials.

Influence of noise in the current state of the NB and implications in its development We verified that the majority of respondents $(87 \%)$ have perception of the "influence of noise in the current clinical status of the NB" $(M=4.12 \pm 0.68 ; M o=4)$ and $90 \%$ has perception of the implications in the development of the NB" ( $M=4.12 \pm 0.68)$, as the binomial test found statistically significant differences between groups in both variables $(p=0.000)$.

\section{Effects on health of parents/relatives and health care professionals}

We found that the majority of health professionals $(77 \%)$ have perception of the "effects of noise on health and well-being of parents/relatives" $(M$ $=3.81 \pm 0.79)$ and $100 \%$ believe that there are "effects on health of professionals" $(M=4.42$ \pm 0.54 ), with statistically significant differences according to the binomial test $(p=0.000)$.

\section{Noise inconvenience in professional per- formance}

For the totality of the sample, the noise bothers the performance of the professionals' duties $(M$ $=3.71 \pm 0.61)$.

\section{Knowledge related to the topic of noise in neonatology and recommended $\mathrm{dB}$}

As regards the assessment of "knowledge related to the topic of noise", we found that $73 \%$ report possessing an appropriate level of knowledge ( $M$ $=2.77 \pm 0.51)$, observing statistically significant differences between those who report possessing an appropriate level of knowledge and those who report not possessing $(p=0.001)$, according to the binomial test.

As regards the "knowledge related to the recommended $\mathrm{dB}$ values" for a NICU, we found that the majority of the sample (58\%) has little knowledge about the recommended $\mathrm{dB}$ values $(M=2.29 \pm 0.75)$ and the binomial test verified no statistically significant differences between health professionals who acknowledge an adequate level of knowledge about the recommended $\mathrm{dB}$ values as opposed to the group that does not acknowledge (adequate level of knowledge; $p=0.332$ ).

\section{Perceiving whether noise is higher than the recommended}

We found that the majority (98\%) considers that the level of existing noise in the unit exceeds the recommended values for a unit with these characteristics $(M=3.63 \pm 0.56)$, with statistically significant differences between the group of professionals who considered that the noise is higher than the recommended values and those who did not consider (binomial $p$ $=0.000)$.

\section{Concern about noise}

Regarding the perception of professionals about the "concern about noise" in the unit, we found that the majority of respondents $(90 \%)$ reported that they care at some moment in time with the noise in the unit $(M=3.17 \pm 0.62)$, the binomial test verifying statistically significant differences with the group that is not concerned with the noise $(p=0.000)$.

\section{Contribution of the behavior of professionals}

When asked about the contribution of their behavior to the noise in the neonatology unit, the majority of the professionals referred that their behavior contributes to the noise in the unit $(M=2.88 \pm 0.51)$. The binomial test verified statistically significant differences between the group of professionals who believes that their behavior does not influence the noise in the unit (19\%) and those who believe that at some moment in time their behavior affects the noise $(81 \% ; p=0.000)$.

\section{Possibility of noise reduction}

When asked about the "possibility of noise reduction in the neonatology unit" ( $M=3.94$ 
$\pm 0.54)$, the totality of the sample reported that it is possible to reduce (100\%).

\section{Suggestions to improve the noise levels in the neonatology unit}

Three categories resulted from the content analysis performed to the open question about the suggestions for the noise reduction in the neonatology unit: Human resources, Material resources, and Physical structure (Table 2). The expressions of the respondents are mostly related to the category of Human resources and the subcategories of Awareness and training on the topic, Change of procedures, Change of behaviors, and Leadership. We can note some excerpts of the responses: "Training of health professionals and awareness for silence" (Q12); "Training in the field" (Q42); "Awareness of parents and relatives of the NB to speak more quietly" (Q32); "Placement of light signal that illuminates whenever the noise limit is exceeded" (Q1); "To silence the alarms quickly"
(Q11); “To not place objects on top of incubators” (Q11, Q40); "nothing is achieved without good leadership with the encouragement of those who want to change for the better" (Q40).

In the category referring to Material resources, the subcategories of Optimization of alarms and Improvement of other support materials emerged. Suggestions were made, including: "To rectify with greater frequency the alarm volume of equipment" (Q4; Q36); "To swap some equipment that only generates noise such as opening and closing the garbage bin" (Q30); "To place light or less intense signal in doorbell of the access door to the unit" (Q26).

The Physical structure was yet another category that emerged, where respondents reported strategies related to the improvement of management and sonority of spaces: "The dining/ break room of professionals should be located elsewhere" (Q14); “To improve soundproofing of the rooms" (Q3; Q14).

Table 2

Categories, subcategories, and indicators for analysis of suggestions for the improvement of noise in neonatology

\begin{tabular}{|c|c|c|}
\hline Category & Subcategories & Indicators (Enumeration units) \\
\hline \multirow{20}{*}{$\begin{array}{l}\text { Human } \\
\text { resources }\end{array}$} & \multirow{5}{*}{$\begin{array}{l}\text { Awareness and } \\
\text { training in noise }\end{array}$} & Awareness of health professionals in noise topic (7) \\
\hline & & Training in the topic for professionals (10) \\
\hline & & Training and awareness in the topic for NB parents (2) \\
\hline & & Sensor of light alarm for noise (6) \\
\hline & & Monitoring of noise levels in the unit (3) \\
\hline & \multirow{6}{*}{ Change of procedures } & Garbage removal (2) \\
\hline & & Digital records outsider care rooms (1) \\
\hline & & $\begin{array}{l}\text { Management of number of persons in the unit and } \\
\text { care rooms (2) }\end{array}$ \\
\hline & & Organization of care provision (2) \\
\hline & & Decrease of room lighting and incubator cover (2) \\
\hline & & Shift pass-down (1) \\
\hline & \multirow{6}{*}{ Change of behaviors } & Talking more quietly (7) \\
\hline & & Decrease of conversation in care rooms (3) \\
\hline & & Silent or turned off cellphones (3) \\
\hline & & Removal of radios in the unit (4) \\
\hline & & Fast response to equipment alarms (4) \\
\hline & & Not placing items on upper part of incubator (3) \\
\hline & \multirow{3}{*}{ Leadership } & Good leadership (1) \\
\hline & & Surveillance of professionals' behaviors (2) \\
\hline & & Incentive and alert of behaviors (3) \\
\hline
\end{tabular}




\begin{tabular}{lll}
\hline \multirow{2}{*}{$\begin{array}{l}\text { Material } \\
\text { resources }\end{array}$} & $\begin{array}{l}\text { Decrease of alarm volume (12) } \\
\text { Establishing suitable alarm limits in equipment (5) } \\
\text { Sound silencers in assisted ventilation systems (4) }\end{array}$ \\
\cline { 2 - 3 } & $\begin{array}{l}\text { Improvement of other support } \\
\text { materials }\end{array}$ & $\begin{array}{l}\text { Substitution of materials by others less noisy (10) } \\
\text { Change of unit doorbell (6) } \\
\text { Change of service telephone (6) }\end{array}$ \\
\hline $\begin{array}{l}\text { Physical } \\
\text { structure }\end{array}$ & $\begin{array}{l}\text { Change of location of dining room (1) } \\
\text { Improvement of sonority }\end{array}$ & Improme of soundproofing in care rooms (3) \\
\hline
\end{tabular}

\section{Discussion}

The objective of this study was to identify the perception of health professionals about noise in neonatology, using an ad-hoc questionnaire. The analysis of the perceptions about the overall noise showed that $77 \%$ consider the neonatology unit noisy, including some degree of discomfort in the performance of their duties $(100 \%)$ and the notion of discomfort related to the acoustic comfort of the unit (54\%). These results indicate that similarly to the study of Carvalhais et al. (2016), there is a discomfort in the environment of the unit, identifying the noise as a disruptive agent and with negative impact during and after the work.

Regarding the effects of noise, we verified, like Daniele et al. (2012), that the majority of respondents consider that there is an influence on the current state of the NB, on its development, and also on parents and health professionals. The exposure of the NB to high noise levels can cause adverse effects on physiological stability and neurodevelopment. It can contribute to hearing and behavioral disorders, negatively influencing recovery, with a consequent increase of the time of hospitalization (Correia et al., 2014).

We found that the majority of health professionals $(73 \%)$ acknowledge possessing adequate knowledge about the topic of noise, but, similarly to the study by Daniele et al. (2012), the majority $(58 \%)$ has little knowledge about the recommended $\mathrm{dB}$ values for the NICU. Nevertheless, the majority of the professionals $(98 \%)$ consider that the unit exceeds the recommended noise levels and is seemingly aware of the need for intervention of noise control/ reduction in the unit (Degorre et al., 2017; Santana et al., 2015).

We found that $23.1 \%$ of the professionals indicate that most of the times there is a concern about the noise and $65.4 \%$ reported that sometimes they worry. Although the noise causes concern at some moment in time, the majority $(81 \%)$ reported that their behavior contributes in some way to the noise in the unit. Daniele et al. (2012) concluded that the health professionals tried not to cause noise, but the lack of knowledge about the recommended levels and the absence of regular noise monitoring in the unit do not contribute to the maintenance of pro-active and lasting attitudes.

Nurses have the highest perception of noise and those with lower perception are the operational assistants. It is known that the training of nurses requires the acquisition of competencies and responsibilities that allow them to deliver care focused on development, with measures to control the noise (Ferraz, 2017).

We also found that the individuals with $\geq 21$ years of professional experience have a higher perception of noise. However, there were no statistically significant differences. Daniele et al. (2012) also found that those with more experience manifest a greater concept of noise, but with statistically significant differences.

About the noise sources, the professionals reported mostly the environment of the unit and referred the equipment and the NB crying as results also found in the study of Daniele et al. (2012). They also indicated the provision of care/procedures, the telephone/cellphones and radios in the unit, data that confirm the study of Correia et al. (2014) and Carvalhais et al. (2016) who found that $55.8 \%$ of professionals reported the equipment as the primary noise source, followed by the conversations between elements of the team. The fact that professionals have acknowledged the influence of their behavior and activities related to care in the noise of the unit constitutes an essential aspect of reflection.

About the suggestions to improve the noise, 
three main categories emerged, that comprises a set of interdependent actions directed to Human resources, Material resources, and Physical structure. The interventions within the context of Human resources are the most referred, particularly the awareness and training of professionals and parents about the topic of noise with the purpose of being pro-active elements in the process of change in noise levels in the unit. Carvalhais et al. (2016) stated that the training of the team towards the adoption of behaviors that promote noise control in the unit is essential and should be regarded as the first step toward the implementation of a program for the reduction of noise in the NICU. It is known that the structural and behavioral changes can significantly affect the noise level of the NICU and we can act on the latter immediately (Correia et al., 2014; Marques, 2014). In the behavioral changes there was the suggestion of simple measures and so important for the environment in the NICU, such as talking more quietly, removal or gentleness in the use of radios in the unit, decrease of conversations in care rooms, not using cellphones inside the unit, faster response to alarms of equipment and gentleness in handling materials and equipment. These suggestions are similar to those found by Carvalhais et al. (2016), in addition to the limitation of the number of visits and more silence in the shift pass-down. Dinis and Rabiais (2017) conclude that the excess of alarms and false alarms pollute the environment and reduce the rate of response to alarms, increasing the noise.

About the change of procedures, precautions in waste collection, management of the number of people in the unit, and a decrease of lighting in the rooms were mentioned.

Decreasing the lighting in the room has been associated with lower noise levels, observing that this strategy makes people speak more quietly (Daniele et al., 2012).

Only with a policy of continued education and the involvement of all professionals in the search for solutions to the problem will there be effects on the environment of the NICU, transforming the current reality (Santana et al., 2015; Marques, 2014). In this sense, the professionals referring the need for good leadership, the need for and surveillance of behaviors and alerts, or their incentive means that they would be important within the context of a culture of silence that must be adopted by all. Similarly to the study of Carvalhais et al., (2016), we found that the replacement of metallic materials by other plastics can assist in the reduction of noise.

About the Physical structure, the suggestions evoke changes in soundproofing of the rooms and organization of space. Although the physical structure is critical in controlling and reducing the noise of the NICU, it is not sufficient by itself, being necessary a culture focused on the reduction of noise (Santana et al., 2015). This study verified the reduced sample size as a limitation. However, studying a specific unit and involving all the professionals of the team was an excellent opportunity not only to raise awareness for the topic of noise in the NICU but also a way of professionals to report their perceptions and reflect on practices and their context, essential for the necessary structural, behavioral, and organizational changes.

\section{Conclusion}

We noted that the health professionals considered the NICU mostly noisy and uncomfortable, and manifested some degree of discomfort regarding the acoustic comfort of the environment. Most respondents acknowledge the effects of noise on newborns, but also on parents, although they regard the implications in health professionals as the most evident. The surveyed professionals reported that their behavior contributes in some way to the overall noise of the unit, showing some gaps in the knowledge of the recommended values for a NICU. Although they are aware that there may be in their unit higher noise levels than those recommended, they report that it is possible to reduce the noise.

The professionals identified the equipment as the primary noise source, followed by the conversations between elements of the team. In the open response for this question, they mentioned the devices and materials, highlighting the garbage bins, the doorbell, and the unit's telephone

The professional group influences the perception of noise in the unit, and nurses are who have the greatest perception. The professional 
experience influences perception and those with more years of service have a higher perception of the noise in the unit.

This study is relevant because of the awareness of health professionals who work in neonatology units. We considered the implementation of measures essential to promote a more acoustically comfortable environment, contributing to the well-being of the NB, parents, and health professionals. The implementation of strategies to decrease/control noise should focus on different areas, such as Human resources, Material resources, and Physical structure. It is known that intervening in the acoustical environment of the NICU involves costs, time, patience, and teamwork, so we suggest starting with a SWOT analysis (Strengths, Weaknesses, Opportunities, Threats) elaborated by professionals of the service. It is also important to invest in the training of a multidisciplinary team in order to establish and raise awareness for the adoption of effective interventions to control the noise. This study was accompanied by a monitoring of the noise values in the unit whose data will be taken into account in the approach of these suggestions.

We further suggest the exploration of this topic about the noise in neonatology in future researches, including monitoring inside the incubators.

\section{References}

Agência Nacional de Vigilância Sanitária. (2015). Manual: Conforto ambiental em estabelecimentos assistenciais de saúde (Versão 1.1). Brasília, Brasil: Autor.

Bardin, L. (2016). Análise de conteúdo (4a ed.). Lisboa, Portugal: Ediçóes 70.

Caple, C., \& Hurst, A. (2016). Noise and neonatal intensive care. Cinahl information systems, 1-3.

Carvalhais, C., Santos, J., Coelho, M., Xavier, A., \& Silva, M. (2016). Health care staff perception of noise in neonatal intensive care units: A questionnaire survey from NeoNoise project. In P. Arezes, J. S. Baptista, M. Barroso, P. Carneiro, P. Cordeiro, N. Costa ... G. Perestrelo (Eds.), Occupational safety and hygiene (Vol. 4, pp.567-571). Philadelphia, PA: CRC Press, Taylor \& Francis.

Correia, C., Mendonça, A., \& Souza, N. (2014). Produçâo científica sobre ruídos na unidade de terapia intensiva neonatal: Revisão integrativa. Revista Enfermagem UFPE on line, 8(1), 2406-2412. doi:10.5205/relou.5927-50900-1-SM.0807suppl201428.

Coughlin, M. (2017). Trauma-informed care in the NICU: Evidence-based practice guidelines for neonatal clinicians. New York, NY: Springer Publishing Company.

Daniele, D., Pinheiro, E., Kakehashi, T., \& Balieiro, M. (2012). Conhecimento e percepção dos profissionais a respeito do ruído na unidade neonatal. Revista $d a$ Escola de Enfermagem da USP, 46(5), 1041-1047. doi:10.1590/S0080-62342012000500002

Degorre, C., Ghyselen, L., Barcat, L., Dégrugilliers, L., Kongolo, G., Leké, A., \& Tournex, P. (2017). Nuisances sonores en reanimation neonatal: Impact d'un outil de monitorage. Archives de Pédiatrie, 24(2), 100-106. doi: 10.1016/j.arcped.2016.10.023

Dinis, S. M., \& Rabiais, I. C. (2017). Fatores que interferem na resposta dos enfermeiros na monitorização dos alarmes clínicos. Revista Brasileira de Enfermagem, 70(1),172-179. doi:10.1590/0034-7167-2015-0092

Direção-Geral da Saúde. Departamento da Qualidade na Saúde. (2016). Manual de standards: Hospitais (2a ed.). Retrieved from https://www.dgs.pt/ $\mathrm{ms} / 8 /$ pagina. aspx?js=0\&codigoms $=5521 \&$ codigono=02090250AAAAAAAAAAAAAAAA

Ferraz, L. P. (2017). Cuidados centrados no desenvolvimento do recém-nascido prematuro (Master's dissertation). Escola Superior de Enfermagem de Coimbra, Portugal.

Marques, J. (2014). A minimização do ruído como um cuidado desenvolvimental nas unidades de neonatologia. Sinais Vitais, 113, 47-55.

Pineda, R., Durant, P., Mathur, A., Inder, T., Wallendorf, M., \& Schlaggar, B. (2017). Auditory exposure in the neonatal intensive care unit: Room type and other predictors. The Journal of Pediatrics, 183, 5666. doi:10.1016/j.jpeds.2016.12.072

Reeves-Messner, T., \& Spilker, A. (2017). Shh...babies growing: A clinical practice guideline for reducing noise level in the neonatal intensive care unit. Journal of Neonatal Nursing, 23(4), 199-203. doi: 10.1016/j. jnn.2017.02.006

Santana, L., Silva, L., Silva, R., Carvalho, J., Santana, W., Barbosa, L, \& Ruas, E. (2015). Quantificação dos ruídos sonoros em uma unidade de terapia intensiva neonatal. Revista Mineira de Enfermagem, 19(2), 2731. doi:10.5935/1415-2762.20150023

White, R., Smith, J., \& Shepley, M. (2013). Practice guidelines: Recommended standards for newborn ICU design, eighth edition. Journal of Perinatology, 33, S2-S16. doi:10.1038/jp.2013.10 
